\title{
How a Taxonomically-Ambiguous Cyanobiont and Vanadate Assist in the Phytoremediation of Cadmium by Azolla pinnata: Implications for $\mathrm{CKDu}$
}

\author{
D R A M T R Atugoda ${ }^{1}$, L L U Mandakini ${ }^{2}$, N J G J Bandara ${ }^{2} \&$ D Gunawardana ${ }^{1}$ \\ ${ }^{1}$ Department of Botany, University of Sri Jayewardenepura, Sri Lanka \\ ${ }^{2}$ Department of Forestry and Environmental Science, University of Sri Jayewardenepura, Sri Lanka \\ Correspondence: D Gunawardana, Department of Botany, University of Sri Jayewardenepura, Sri Lanka. Tel: \\ 94-1-1285-1526. E-mail: dilanthag_12@yahoo.com.au
}

$\begin{array}{lc}\text { Received: February 6, } 2018 & \text { Accepted: February 26, } 2018 \quad \text { Online Published: March 30, } 2018 \\ \text { doi:10.5539/ep.v7n1p53 } & \text { URL: https://doi.org/10.5539/ep.v7n1p53 }\end{array}$

Note: D R A M T R Atugoda and L L U Mandakini have contributed equally to the work and are entitled to primary authorship of the paper.

\begin{abstract}
We employed scientific tools to investigate the ex situ phytoremediation of cadmium by Azolla pinnata. Azolla pinnata was capable of efficient sequestration of cadmium up to a concentration of $1 \mathrm{ppm}$, though with a visibly high "physiological cost". The sequestration of cadmium (1 ppm) was strongly reduced after 24 hours, in Azolla plants pre-treated with the gram-negative antibiotic erythromycin $(60 \mu \mathrm{g} / \mathrm{l})$, suggesting that the cyanobacterial population was important for phytoremediation. Only the co-treatment of $1 \mathrm{ppm}$ cadmium with $1 \mathrm{ppm}$ vanadate, showed significantly higher phytoremediation $(\mathrm{P}<0.05)$ compared to the "cadmium+erythromycin" treatment. The phytoremediation of Cadmium by the Azolla-Nostoc symbiosis was significantly $(\mathrm{p}<0.05)$ improved by the addition of citrate at $10 \mathrm{ppm}$ in the presence of $1 \mathrm{ppm}$ vanadate, compared to the $1 \mathrm{ppm}$ cadmium only treatment. We hypothesize that citrate acting either as "vanadophores" or working as a cofactor in the Homocitrate Synthase enzyme, facilitates remediation of cadmium. When phylogeny was inferred using Homocitrate Synthases, the cyanobiont was approximated to a taxonomical twilight zone between Nostoc and Anabaena, although showing more proximity to the Anabaena cluster. It is proposed here that the cyanobacterial contribution appears to be crucial for the ability of Azolla pinnata to efficiently remediate cadmium and a "helping hand" appears to be provided by a vanadate dependent mechanism, which is likely to be nitrogen fixation. The association between vanadate-assisted phytoremediation by Azolla pinnata and the heightened bioavailability of vanadium in $\mathrm{CKDu}$ endemic areas, could serve as a vital stepping stone in developing a biological solution to $\mathrm{CKDu}$.
\end{abstract}

Keywords: Azolla pinnata, macrophyte, vanadium, cadmium, Chronic Kidney Disease of an Unknown etiology $(\mathrm{CKDu})$, cyanobacteria

\section{Introduction}

Many aquatic environments are polluted by heavy metals due to a myriad of reasons, including, industrial effluents, leaching of heavy metals from soil or bedrock and agrochemical usage in contemporary agriculture. Heavy metals are chemical elements possessing a high atomic weight and densities five times greater than water (Sood et al., 2012).

One technology that is widely utilized for remediation of polluted environments is phytoremediation which is based on exploiting a plant's intrinsic mechanisms to accumulate or detoxify heavy metals from the soil or from aquatic environments (Salt et al., 1995). Phytoremediation is a low cost green technology and has been shown to be effective in diverse aquatic systems including reservoirs and ponds. Certain plants known as hyper accumulators are capable of absorbing heavy metals which have little importance for plant metabolic processes (Cheng et al., 2016). These hyper accumulating plants which possess the capacity to absorb non-essential heavy metals are suitable candidates for efficient phytoremediation. 
Macrophytes are defined as plants that float on the water surface with submerged roots and are potential candidates of phytoremediation as they demonstrate strong capacities to absorb non-essential heavy metals and concentrate them in tissues (Salt et al., 1995). In addition, the rapid proliferation and direct contact of aquatic macrophytes with the contaminated environment facilitates the purification process and ensures the sanitation of polluted water bodies.

Azolla pinnata is a small free-floating aquatic fern that lives in a mutual symbiosis with a cyanobacterium (Nostoc azollae) that is able to fix atmospheric nitrogen (Talley et al., 1977). Azolla is cultivated widely in Asian rice terraces to ensure that there is a constant supply of nitrogen to the soil. There are many unanswered questions on the Azolla-Nostoc azollae symbiosis, including the exact nature of the nitrogenase present in the cyanobacterial partner. The questions that remain even today, include, whether there are major and minor cyanobionts with different nitrogenase systems present in association with Azolla (Meeks et al., 1988, Peters, 1991), whether a single nitrogen fixation system in Nostoc azollae is molybdenum or vanadium reliant (Thiel, 1993) or whether a single cyanobiont contains both types of nitrogenases - with molybdenum and vanadium dependency. In a noteworthy discovery, it has been shown that the photobiont Nostoc in the lichen symbiosis with the fungal partner Peltigera, has a vanadium-dependent nitrogen fixation system (Darnajoux et al., 2014). It has also been suggested that the vanadium-dependent nitrogenase system could be widespread in symbiotic systems, including that of the Cycas-Nostoc symbiosis (Hodkinson et al., 2014). The cyanobiont inside Azolla appears to be a victim of an identity crisis, since numerous identities have been attributed to this symbiont, including the genera names Nostoc, Anabaena and Trichormus and there still seems to be no consensus on this rather dubious name calling (Baker et al., 2003; Pereira and Vasconcelos, 2014).

In this study, we have assessed the phytoremediation potential of Azolla pinnata in an ex-situ tank-based experimental system, where its phytoremediation capacity for environmentally-relevant cadmium concentrations was investigated as the initial research goals of a study. We also have undertaken the deciphering of the potential contribution of the Nostoc cyanobiont and the role of vanadium as vanadate to the phytoremediation of cadmium by the Azolla water fern. This study is of strong importance to Sri Lanka, due to the presence of a Chronic Kidney Disease of an Unknown etiology (CKDu) among paddy farmers in Sri Lanka which has been proposed partially to arise from exposure to cadmium (Wimalawansa, 2016). Interestingly, there has also been data derived on the increased presence and bioavailability of vanadium in soils of CKDu endemic areas of Sri Lanka and their supposed correlation to CKDu (Jayawardana et al., 2014).

\section{Materials and Methods}

\subsection{Cultivation and Harvesting}

For the phytoremediation experiments, a series of $0.5 \mathrm{ppm}, 1.0 \mathrm{ppm}, 1.5 \mathrm{ppm}, 2.0 \mathrm{ppm}, 2.5 \mathrm{ppm}$ and $3.0 \mathrm{ppm}$, was used for cadmium (cadmium chloride), on par with the environmental levels of the respective heavy metal. Rectangular glass aquaria with the dimensions of $28 \mathrm{~cm} \times 15 \mathrm{~cm} \times 10 \mathrm{~cm}$ were used to perform the experiment. Aquaria were filled with $2 \mathrm{~L}$ of each treatment solution in triplicates and distilled water, and the absence of the metal was used as the control. $1 \mathrm{~g}$ of Albert solution was added into each aquarium to supply the nutrient requirements and $\mathrm{pH}$ of the solutions were maintained between 6.5-7.5 throughout the experiment by titration with $\mathrm{HCl}$ and $\mathrm{NaOH}$.

Healthy and matured Azolla plants were selected, rinsed with distilled water and blotted on filter papers to remove adherent water and $1 \mathrm{~g}$ of the water fern was laid on the surface of each aquarium. All the experiments were run for a 1 or 7 day periods. $20 \mathrm{ml}$ water samples were withdrawn from each individual replicate at 12 or 24 hour intervals. Distilled water was added based on necessity, to compensate for the water loss through evaporation.

For the treatments with Vanadate and Molybdate, the salts, $\mathrm{NH}_{4} \mathrm{VO}_{3}$ and $\left(\mathrm{NH}_{4}\right)_{6} \mathrm{Mo}_{7} \mathrm{O}_{24}$, were used at the given treatment levels ( 1 or $10 \mathrm{ppm}$ ). Three series of experiments (Figure 1, 2 and 3) using either $\mathrm{NH}_{4} \mathrm{VO}_{3}$ or $\left(\mathrm{NH}_{4}\right)_{6} \mathrm{Mo}_{7} \mathrm{O}_{24}$ were conducted in that way. In addition, we also tested the cadmium absorption with $1 \mathrm{ppm}$ zinc chloride and $1 \mathrm{ppm}$ sodium fluoride, to assess ionic competition (zinc) and inhibition (fluoride) of transporter ATPases on cadmium absorption. The treatments with erythromycin were conducted by treating the relevant tanks with $60 \mu \mathrm{g} / \mathrm{ml}$ of erythromycin (Schor-Fumbarov et al., 2005) for three days prior to the supplementation of the cadmium salt.

\subsection{Atomic Absorption Spectrometry}

Water samples from tanks were filtered with Whatmann No.1 filter papers and analyzed by Flame Atomic Absorption Spectrometer (FAAS, GBC 932 plus) for cadmium. Dried Azolla biomass digested by wet digestion 
method according to Kalra (1998), were also analyzed by FAAS (GBC 932 plus) to determine the metal concentrations in Azolla tissues.

\subsection{Calculations}

\section{Relative growth}

The relative growths of the plants exposed to the treatment solutions were calculated using the initial fresh weights and final fresh weights of Azolla biomass as follows.

\section{Removal efficiency}

$$
\text { Relative growth }=\frac{\text { Final fresh weight }}{\text { Initial fresh weight }}
$$

The removal percentage of metal ions by Azolla was determined by using the initial metal concentrations of the treatment and the final concentrations at the end of the experiment.

$$
\text { Removal efficiency }=\frac{\text { (Initial metal concentration }- \text { Final metal concentration }) \times 100}{\text { Initial metal concentration }}
$$

\section{Metal uptake capacity}

The accumulation of metal ions in Azolla tissues was calculated by using the dried weights. The metal concentrations of digested biomass were calculated as follows.

$$
\text { Metal uptake }(\mathrm{mg} / \mathrm{kg})=\frac{\text { Metal concentration of the dried biomass }(\mathrm{mg} / \mathrm{l}) \times \text { Total diluted volume }(\mathrm{ml})}{\text { Dry weight }(\mathrm{g})}
$$

(Bediako, 2013)

\section{Bio concentration factor}

$$
\text { Bio concentration factor }=\frac{\text { Metal concentration of the dried biomass }(\mathrm{mg} / \mathrm{l}) * 1000}{\text { Initial concentration of the metal in the external solution }(\mathrm{mg} / \mathrm{l})}
$$

(Thayaparan et al., 2013).

\subsection{Phylogenetic Analyses}

A neighborhood Joining tree for 19 homocitrate synthase protein sequences comprising the genera Nostoc and Anabaena (downloaded from NCBI), was created using DAMBE (Data Analysis in Molecular Biology and Evolution) version 5.6.9 (Xia and Xie, 2001), using the Calothrix homocitrate synthase sequence as the outgroup. Relationships between adjacent nodes were based on bootstrap support from 500 pseudo-replicates.

A separate phylogenetic tree was created using the Phylogeny.fr platform (Dereeper et al., 2008). Once again, the same 19 Nostocales homocitrate synthase protein sequences from the NCBI database (Anabaena - 10; Nostoc8; Calothrix -1 (outgroup)) were used for the phylogenetic inferences. The sequences were aligned with the program Muscle (V.3.8.31) and ambiguous regions (i.e. containing gaps and/or poorly aligned sequences) were removed with Gblocks (v0.91b). The remaining sequences used to reconstruct a phylogenetic tree, using the maximum likelihood method implemented in the PhyML program (v3.1/3.0 aLRT) and the tree was viewed using graphical representation with TreeDyn (v198.3).

\subsection{Statistical Analyses}

Minitab (version 16) was used to analyze the data obtained from our ex-situ experiments. One way ANOVA (Analysis of Variance) was used to compare the treatment means. Normality assumptions of the data were tested using residuals. Tukey test was used for multiple comparisons and 5\% level of significance was used for all analyses.

\section{Results and Discussion}

Azolla pinnata possesses strong capacity to hyperaccumulate heavy metals from polluted water bodies. Although, the phytoremediation abilities of Azolla pinnata in quenching selective heavy metal ions have been demonstrated before (Rai, 2008), there are existing questions on the ability of the Azolla-Nostoc symbiosis to phytoremediate cadmium polluted waterways, especially the contribution of the cyanobiont to phytoremediation. Some of the existing questions are,

1) How efficient is Azolla pinnata in environmentally-relevant ranges of cadmium?

2) Is the cyanobiont population significant to the phytoremediation mechanisms employed? 
3) Does vanadium, widely present in heightened quantities in CKDu areas, facilitate the phytoremediation of cadmium by Azolla pinnata?

4) Is cadmium absorbed in competition with zinc, as in higher plants?

5) What is the true identity of the cyanobiont inside Azolla pinnata?

To answer the above questions, a tank based experimental system was employed to determine the extent to which cadmium would be sequestered by Azolla pinnata in a time-course study. Among CKDu endemic areas, the highest cadmium level from reservoir water was obtained from Ambagaswewa in Medirigiriya (0.0007 ppm) while Giradurukotte which is considered as a high CKDu region had $0.0003 \mathrm{ppm}$ mean of cadmium, both far lower than what was employed in our ex situ studies (Chandrajith et al., 2012). Outside of the CKDu endemic areas, the cadmium concentration falls even lower, such as in reservoirs of the wet zone of Sri Lanka, where the maximum recorded concentration is 0.0005 ppm (Chandrajith et al., 2012). However in lake sediments in the dry zone $3.243 \mathrm{ppm}$ has been recorded for cadmium (Chandrajith et al., 2012). Accordingly, we employed a 0-3 ppm concentration range for cadmium in our ex-situ tank-based experimental system.

\subsection{The Phytoremediation Efficiency of Azolla Pinnata in Environmentally-Relevant Ranges of Cadmium}

Among the treatments, the highest Cadmium removal efficiencies were observed in the $0.5 \mathrm{ppm}$ and $1 \mathrm{ppm}$ treatments, where $88 \%$ and $76 \%$ removal efficiencies were recorded after 7 days of treatment (Table 1). The calculated BCFs of the $0.5 \mathrm{ppm}$ and $1 \mathrm{ppm}$ treatments were above 1000, suggesting efficient phytoremediation (Table 1). Generally it is acknowledged that a plant useful for phytoremediation should have BCF values greater than 1000 for the specific heavy metal ion (Zayed et al., 1998) In contrast, at concentrations above 1ppm, the calculated BCFs were well below 1000. Azolla plants exposed to the $0.5 \mathrm{ppm}$ treatment in this work, showed a relatively strong growth of 1.95 (only a $12 \%$ reduction in growth compared to the control) while in all other treatments $(1,1.5,2,2.5,3 \mathrm{ppm})$, there was significant growth reductions recorded $(46.8-53.1 \%)$, with visible chlorophyll degradation due to the discoloration of fronds.

Cadmium, which is both a residue of agrochemicals and industrial effluents, has been suggested by the World Health Organization as one of the primary candidates for the etiology of $\mathrm{CKDu}$ - a progressive chronic disease found in Sri Lankan that has resulted in many fatalities in the dry zone of the country. Therefore, it appears that Azolla pinnata is an efficient tool for the removal of cadmium, below $1 \mathrm{ppm}$, from polluted water bodies.

\subsection{Significance of the Cyanobiont to Phytoremediation}

We took $1 \mathrm{ppm}$ cadmium as the standard for the next series of experiments to assess the role of the cyanobacterium Nostoc azollae to the phytoremediation of cadmium by Azolla pinnata. When Azolla pinnata (1g) was pre-incubated with $60 \mu \mathrm{g} / \mathrm{ml}$ of erythromycin for three days and then treated with $1 \mathrm{ppm}$ cadmium, there was a clear reduction, after day 1 , in the phytoremediation capacity of the water fern compared to the $1 \mathrm{ppm}$ cadmium-only treatment (Figure 1). Statistically though $(\mathrm{P}<0.05)$, the $1 \mathrm{ppm}$ cadmium only treatment was not different to the 'cadmium + erythromycin' treatment. It was evident that in the absence or reduction of Nostoc azollae populations, there was a clear and strong reduction in the sequestration of cadmium by the Azolla pinnata-Nostoc azollae symbiosis, demonstrating that Nostoc populations were vital for the phytoremediation by this joint-symbiotic system. Cadmium is sequestrated primarily by a family of proteins called metallothioneins (Isani et al., 2014). The Azolla water fern codes for at least one metallothionein (Schor-Fumbarov et al., 2005) and when the Nostoc azollae genome was mined by bioinformatics tools, we unearthed one metallothionein encoded by the cyanobacterial genome. This protein, which is 43 amino acids in length, belongs to family 14 of metallothioneins, with a sequence pattern K-C-A-C-x(2)-C-L-C, that distinguishes its identity within this family (NCBI/Interpro Databases). It is possible that the loss or reduction of the cyanobacterial metallothionein could have lessened the overall phytoremediation potential of the Azolla pinnata-Nostoc azollae symbiosis. Another likely possibility is that the "protein status" of the water fern was compromised due to depletion of nitrogen fixation due to the loss or reduction of Nostoc azollae populations, including the metallothionein footprint of the symbiosis.

\subsection{The Role of Vanadate in Phytoremediation}

Incubation of $1 \mathrm{ppm}$ cadmium with $1 \mathrm{ppm}$ vanadate, resulted in a strong statistically-significant reduction in aquatic cadmium by the Azolla pinnata-Nostoc azollae symbiosis, compared to the 'erythromycin + cadmium' treatment (Figure 1). The role of vanadate to cadmium sequestration can be objectified using two alternate hypotheses. Vanadate possesses the capacity to inhibit the P-type heavy metal ATPases which are involved in the accumulation of cadmium in higher plants (Eren and Arguello, 2004). Whether Azolla pinnata possesses such heavy metal ATPases cannot be elaborated in the absence of genome information on this water fern. Our results, 
however too, did not agree with the above hypothesis since the phytoremediation potential of cadmium by the Azolla pinnata-Nostoc azollae symbiosis was improved by the addition of $1 \mathrm{ppm}$ vanadate (Figure 1). A second hypothesis proposes that like the Cycas-Nostoc and Peltigera-Nostoc symbioses, the Azolla pinnata-Nostoc azollae symbiosis too contains a vanadium-centered nitrogenase system (Hodgkinson et al., 2014).

It is suggested here that vanadate confers an advantage to the Azolla pinnata-Nostoc azollae system, either directly to the plant, directly to the Nostoc population or both, although considering vanadium is not even a micronutrient to plant systems, the first argument is unlikely to be true. In correlation to the recent discovery that Nostoc found in Peltigera, and inferred so in other symbiotic systems, possess vanadium dependency (Hodkinson et al., 2014), we suggest here that the growth advantage is likely to be conferred by the enhancement of nitrogen fixation performed by the vanadium dependent nitrogen fixation system in the Nostoc cyanobiont. However, we cannot eliminate the role of ammonium ions in lending a helping hand to the phytoremediation, similar to the hypothesis for the involvement of vanadate in the symbiotic health of the association.

In addition, we also tested the phytoremediation capacity of the symbiosis in its regulation by fluoride ions. This was performed using triplicate tanks containing fluoride at $1 \mathrm{ppm}$. Fluoride ions are known to alter plasma membrane associated $\mathrm{H}^{+}$ATPases ( $\mathrm{P}$ type) and vacuolar membrane associated $\mathrm{H}^{+}$ATPases (V type) (Bauntiyal and Sharma, 2014) and we tested whether, these alterations extend to inhibitory effects on the selective absorption of cadmium through heavy metal ATPases. Another point needing validation was whether the presence of fluoride ions, which has been shown to be significantly increased in selective CKDu areas (Wasana et al., 2016), plays a regulatory role in cadmium quenching. However, we did not see any inhibition to cadmium absorption by fluoride ions, neither did we see any advantage given by the fluoride ions to the phytoremediation potential of the symbiosis.

We also wished to observe whether the vanadium-dependent nitrogenase was exclusive or whether it was part of a bi-enzyme system within one population of cyanobacteria or perhaps even two populations - major and minorcontaining two distinct nitrogenases (vanadium and molybdenum types). To test this hypothesis, we took a tank based growth (wet weight) experiment to ascertain whether, the increase of biomass of Azolla pinnata over time, is vanadate (as the source of vanadium) or molybdate (as the source of molybdenum) dependent, or both. We also did controls with equal strength ammonium ions as ammonium chloride, to find out whether the increases in wet weight, are vanadium or molybdenum dependent, or if growth improvements are due to nitrogen supply, by the respective ammonium salts (this was due to both salts we employed in this study being ammonium salts ammonium vanadate/ammonium molybdate). As shown in Figure 2(a), we can clearly see that both molybdate and vanadate were able to increase the wet weight of Azolla pinnata, compared to the ammonium chloride controls, although not significantly. We too observe that ammonium ions (as supplied as ammonium chloride) can induce increases in wet weight of Azolla compared to the distilled water only control. It is noteworthy, that in a study performed by Ito and Watanabe in 1983, they showed that, at a $10 \mathrm{mM}$ concentration of ammonium chloride, there is no significant inhibition of acetylene reduction, even after 2 days, which means that at concentrations of $0.183 \mathrm{ppm}$ and $0.103 \mathrm{ppm}$ of ammonium ions, as used in this study, there is unlikely to be any effect on biological nitrogen fixation. Therefore, we conclude that both ammonium and vanadate, help in the phytoremediation of cadmium, through improving the protein status of the Azolla-Nostoc symbiosis.

To assess the role of vanadate in the absence of ammonium, we conducted a triplicate experiment with Azolla plants, where both sodium vanadate (1 ppm vanadate) and ammonium vanadate (1 ppm vanadate) were used individually and compared with a distilled water only control. Here, we did not add Albert solution and consequently the plants showed negative growth, although partially. The tank series (triplicates) that were supplemented with sodium vanadate (1 ppm vanadate) and ammonium vanadate (1 ppm vanadate) showed a higher capacity to maintain their wet weight (12 and 13\% more) compared to the distilled water only control (Figure 2 (b)).

It is suggested from our findings that the water fern perhaps may use two separate nitrogenase systems. Whether the two nitrogenase systems are found in one cyanobiont population or two, requires further study. We were only able to mine the molybdenum dependent nitrogenase alpha-subunit from Nostoc azollae and not the vanadium counterpart, from sequence resources in the NCBI database (data not shown). Hybridization studies with the Anabaena variabilis ATCC 29413 vanadium-dependent nitrogenase DNA (Vnf genes) has demonstrated that the Nostoc cyanobionts harbored inside the Azolla fronds contain DNA of partial similarity to the bacterial vanadium nitrogenase subunit genes (Thiel, 1993). This finding supports our observations that vanadate as vanadium could provide an advantage to phytoremediation in the Azolla-Nostoc azollae symbiosis through nitrogen fixation. 


\subsection{Competition between Cadmium and Zinc for Absorption by Azolla}

We also tested the accumulation of $1 \mathrm{ppm}$ cadmium in the presence of $1 \mathrm{ppm}$ zinc. Zinc is a co-factor for more than 300 enzymes and an even higher number of transcription factors, and is therefore considered an essential micronutrient (Frassinetti et al., 2006) One of the key mechanisms that heavy metals exert their toxicities is through their competition against essential metals for absorption at root surfaces or transport in planta. In the case of cadmium, it competes directly with zinc for transport in higher plants. In Arabidopsis thaliana, 8 Heavy Metal ATPases (HMAs) have been identified, of which HMA2, HMA3 and HMA4 have been shown to be involved in the transport of zinc and cadmium (Takahashi et al.., 2012). From our results, it is clear that the co-treatment of cadmium with zinc did not have a significant impact on the cadmium absorption by the Azolla-Nostoc azollae symbiosis (Figure 3), although the level of cadmium in the $1 \mathrm{ppm}$ zinc co-treatment after 24 hours, is marginally higher compared to the co-treatment of vanadate or molybdate, suggesting some level of competition. We were also not able to find HMA family proteins in the limited Azolla resources available in the web and until at least one Azolla genome is fully sequenced we are unable to mine the HMA family members from the genomes of any Azolla species.

\subsection{The Role of Citrate to Phytoremediation and Phylogeny Based on Homocitrate Synthases}

We also conducted a triplicate tank experiments with ' $1 \mathrm{ppm}$ vanadate $+10 \mathrm{ppm}$ citrate' and several other treatments, to remediate $1 \mathrm{ppm}$ cadmium (Figure 3). Citrate is a negatively charged organic compound which complexes with vanadium as well as vanadate and vandyl ions. Citrate too forms complexes with cadmium (Capone et al., 1986). The presence of $10 \mathrm{ppm}$ citrate on top of $1 \mathrm{ppm}$ vanadate, significantly $(\mathrm{p}<0.05)$ aided the phytoremediation by the Azolla pinnata-Nostoc azollae symbiosis, compared to the 1ppm cadmium only control (Figure 3). Citrate can (1) increase the uptake of vanadium by acting as "vanadophores" for the cyanobacterial population (Rehder, 2008) (2) Increase the uptake of cadmium in Azolla roots through the 'cadmium-citrate' complexes either 'through carry and release' or more permanent complexation functions (McLean et al., 2013) (3) increase the folding and production of the nitrogenase enzyme complex by its structural analogy to homocitrate, an essential co-factor for the nitrogenase enzyme function (Allen et al., 1994). All three theories are possible, as there is literature evidence on these proven biological actualities.

Nitrogen-fixing cyanobacteria contain homocitrate synthases (encoded by the nif $V$ genes), which are responsible for the intrinsic synthesis of homocitrate for nitrogen fixation, but are surprisingly absent in symbiotic rhizobia, although present in Frankia species (Hakoyama et al., 2009). Therefore, homocitrate synthases (proteins encoded by the nif $V$ genes), due to their rather exclusive presence in cyanobacteria, aerobic free-living bacteria such as Azotobacter and gram-positive Frankia among nitrogen fixers, appeared to be an interesting target for a phylogenetic study, to ascertain the true identity of the cyanobiont - whether it is closer to Nostoc or Anabaena. In addition, unlike the core $\mathrm{Fe}-\mathrm{Mo} / \mathrm{V}$ protein, there is no differences in co-factor binding or function of the homocitrate synthases and the differences within protein sequences can be attributed largely to substitutions caused by evolutionary forces, based on the molecular clock hypothesis.

Using NCBI resources, we downloaded 19 sequences belonging to the order Nostocales, 18 of which belonged to the genera Nostoc and Anabaena and used the homocitrate synthase sequence from the genus Calothrix to root the phylogenetic tree (see section 2.4). According to the phylogenetic trees (Figure 4 and 5), the Nostoc azollae was found as a monophyletic grouping that also included Anabaena cylindrica and Anabaena sp PCC 7108, which demonstrated that these two free-living species were the closest relatives of Nostoc azollae, when the homocitrate synthase protein is used for phylogenetic inferences. Interestingly, both Anabaena cylindrica $s p$ PCC 7122 and Anabaena spp PCC 7108 were shown in a separate study to be found together with Nostoc azollae as a monophyletic cluster (Komarek et al., 2014). Furthermore, both Anabaena cylindrica sp PCC 7122 and Anabaena sp PCC 7108 were shown in another study to be found in a phylogenetic twilight zone between Anabaena and Aphanizomenon on one side and Cylindrospermum, Nodularia and Nostoc strains on the other (Lyra et al., 2001). It seems we too have derived similar conclusions on the identity of the cyanobiont inside Azolla pinnata, i.e. the cyanobacterial population harbored within Azolla falls in a twilight zone between Nostoc and Anabaena clusters, yet is more phylogenetically closer to the Anabaena cluster than the Nostoc grouping. Furthermore, when we tested the presence of the FEN1 gene of Lotus japonica (encoding for a plant homocitrate synthase) in the genomes of both Azollacaea and Cycadacae, both families that have symbiotic relationships between filamentous cyanobacteria of the order Nostocales, which yielded that there were no homologs of the enzyme present in either plant family. Therefore it appears that the homocitrate synthase gene is found in the symbiotic cyanobiont harbored within the leaf cavities of Azolla and is likely to play a role in nitrogen fixation. 


\section{Conclusions}

We have shown in this study that cadmium up to $1 \mathrm{ppm}$ can be efficiently remediated by Azolla pinnata. We have also shown that the phytoremediation by the Azolla pinnata water fern is dependent on the health of the cyanobiont populations. Vanadate at $1 \mathrm{ppm}$, when present in the immediate environment, also appears to provide an advantage in phytoremediation. We also provide evidence that $10 \mathrm{ppm}$ citrate increases significantly the phytoremediation of cadmium in combination with $1 \mathrm{ppm}$ vanadate, compared to a treatment containing only 1 ppm cadmium. It was also demonstrated by phylogenetic inferences using the homocitrate synthases that the cyanobiont in Azolla pinnata is found within the taxonomically-ambiguous zone between Anabaena and Nostoc, but showing a higher alignment to the Anabaena grouping. In conclusion, it is clear from our data, that the cyanobiont and vanadate are important for the efficient phytoremediation of cadmium by the water fern Azolla pinnata. The role of citrate in the enhancement of phytoremediation needs to be explored further, as there are a handful of hypotheses on the role of citrate in heavy metal transport and nitrogen fixation.

Whether these ex-situ findings can be extrapolated to a field setting, needs to be resolved by undertaking multi-location, in-situ studies in cadmium polluted paddy fields from CKDu endemic areas. The role of vanadate in improving the phytoremediation of cadmium by Azolla pinnata is a noteworthy finding considering there is a heightened presence and bioavailability of vanadium in CKDu endemic lands. Our findings support a model where vanadium or vanadate improves symbiotic health, possibly through nitrogen fixation, which in turn enhances the remediation of cadmium. So far, CKDu has claimed more than 20000 lives, and this study we hope, will expedite the search for a biological solution to this contemporary crisis.

Table 1. Mean values of removal efficiency, relative growth, uptake and bio concentration factor of cadmium by Azolla pinnata after 7 days of treatment

\begin{tabular}{|c|c|c|c|c|c|c|c|}
\hline & Control & $0.5 p p m$ & $1.0 \mathrm{ppm}$ & $1.5 \mathrm{ppm}$ & 2.0ppm & $2.5 \mathrm{ppm}$ & 3.0ppm \\
\hline $\begin{array}{c}\text { Removal } \\
\text { efficiency (\%) }\end{array}$ & 0 & 88 & 76 & 75 & 76 & 57 & 43 \\
\hline $\begin{array}{l}\text { Relative } \\
\text { growth }\end{array}$ & 2.22 & 1.95 & 1.12 & 1.18 & 1.041 & 1.11 & 1.08 \\
\hline $\begin{array}{c}\text { Cd uptake } \\
\text { (mg/kg) }\end{array}$ & 1.73 & 560.03 & 1041.19 & 1199.03 & 1587.26 & 1545.48 & 1792.19 \\
\hline BCF & - & 1120.06 & 1041.19 & 799.35 & 793.63 & 618.19 & 597.40 \\
\hline
\end{tabular}




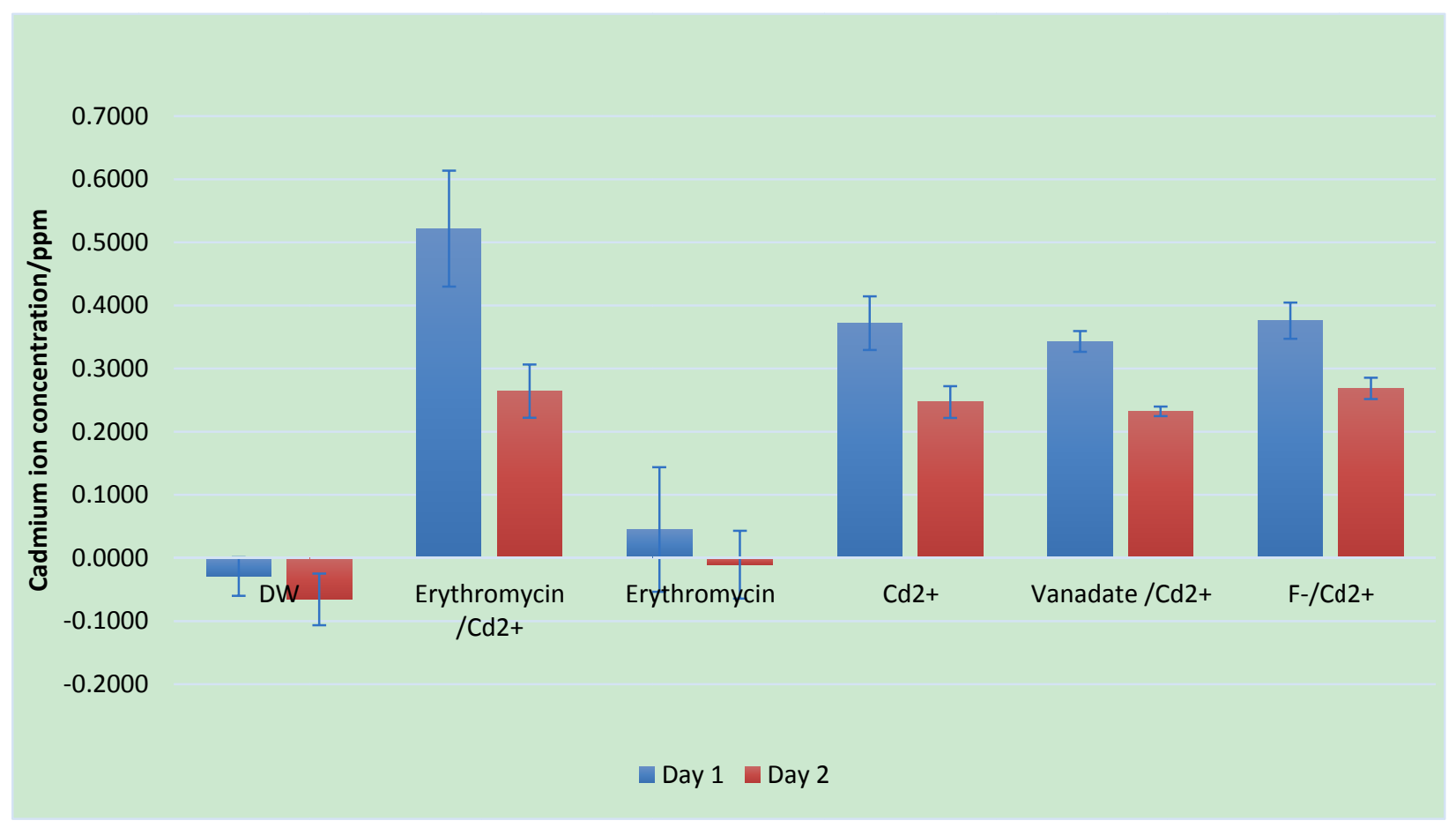

Figure 1. Cadmium concentration (ppm) 24 hours (1 day) and 48 hours (2 days) after treatment, as determined by atomic absorption spectroscopy. Only the "cadmium+vanadate" treatment (day 1) was significantly different

$(\mathrm{p}<0.05)$ to the "erythromycin+cadmium" treatment (day 1), when assessed through statistical pairwise comparisons. (DW - distilled water only/control, $\mathrm{Cd} 2+$ - Cadmium; F- - Fluoride)

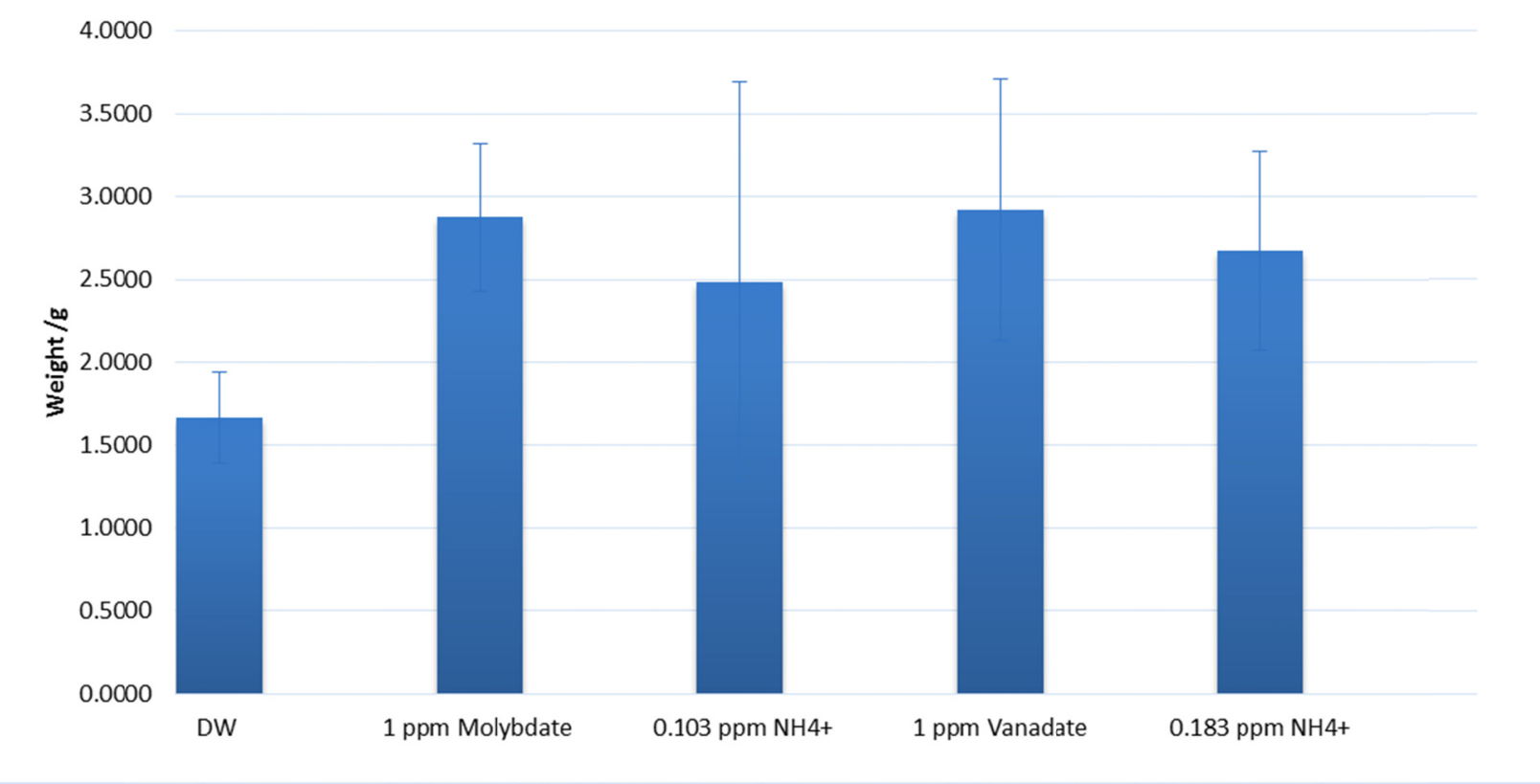

Figure 2 (a). Wet weight of Azolla pinnata as measured after 7 days of growth in either ammonium vanadate, ammonium molybdate or ammonium chloride treatments, containing all essential nutrients. The wet weights signifying growth of Azolla, were not statistically significant to each other, in any treatment pairs, when multiple pairwise comparisons were performed. The ammonium concentrations were similar between the following

treatments - between ammonium molybdate ( $1 \mathrm{ppm}$ molybdate) and ammonium chloride $(0.103 \mathrm{ppm}$ ammonium in both treatments); between ammonium vanadate (1 ppm vanadate) and ammonium chloride in separate triplicate tanks ( 0.183 ammonium in both treatments). 


\begin{tabular}{|c|c|c|c|}
\hline & Control & $\begin{array}{c}\text { Sodium Vanadate } \\
\text { (Vanadate 1 } \mathbf{~ p p m})\end{array}$ & $\begin{array}{c}\text { Ammonium Vanadate } \\
\text { (Vanadate 1 ppm) }\end{array}$ \\
\hline Wet Weigh (g) & $0.7868+/-0.1355$ & $0.8798+/-0.0603$ & $0.8929+/-0.0407$ \\
\hline Wet Weight (percent) & $100 \%+/-17.23$ & $111.81 \%+/-7.67$ & $113.48+/-5.17$ \\
\hline
\end{tabular}

Figure 2 (b). A tank experiment was performed to assess the role of vanadate in the absence of ammonium ions (as a sodium salt). $1 \mathrm{~g}$ of Azolla plants were used in the wet weight experiment, in a triplicate tank system containing, distilled water (only), "distilled water + sodium vanadate", "distilled water + ammonium vanadate", where a vanadate concentration of $1 \mathrm{ppm}$ was used. We ensured that the tanks were only supplemented with the vanadate salts and there was no other nutrient source available.

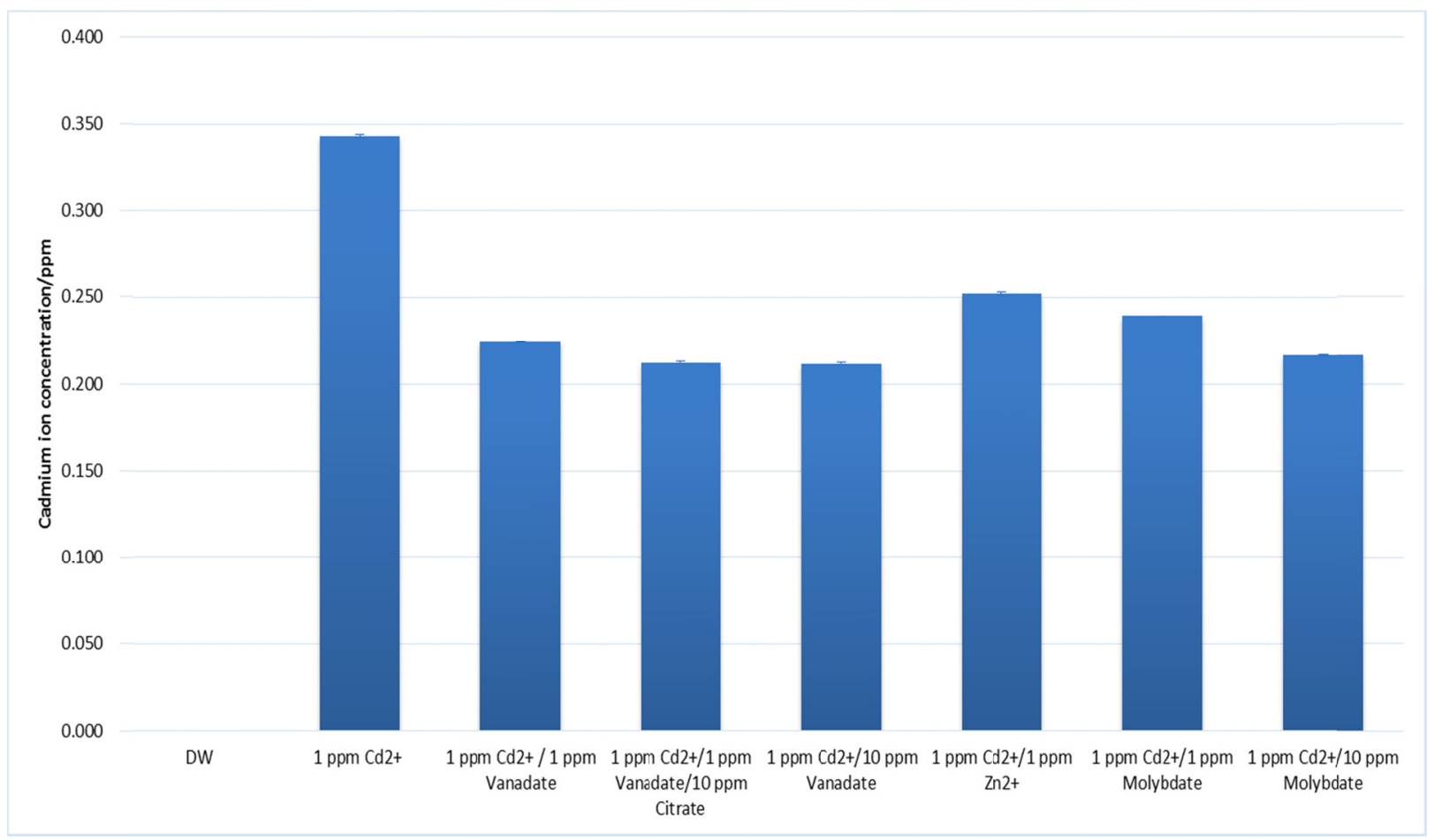

Figure 3. Cadmium concentrations (ppm) 24 hours (1 day) after treatment as determined by Atomic absorption spectroscopy (starting concentration $-1 \mathrm{ppm}$ cadmium). The specific treatments are indicated below the bar graphs. Only the "1 ppm Cadmium $+1 \mathrm{ppm}$ Vanadate $+10 \mathrm{ppm}$ Citrate" treatment (day 1) was significantly different $(\mathrm{p}<0.05)$ to the $1 \mathrm{ppm}$ Cadmium only treatment (day 1$)$, when assessed through statistical pairwise comparisons. (Cd2+ - cadmium, DW - Distilled Water) 


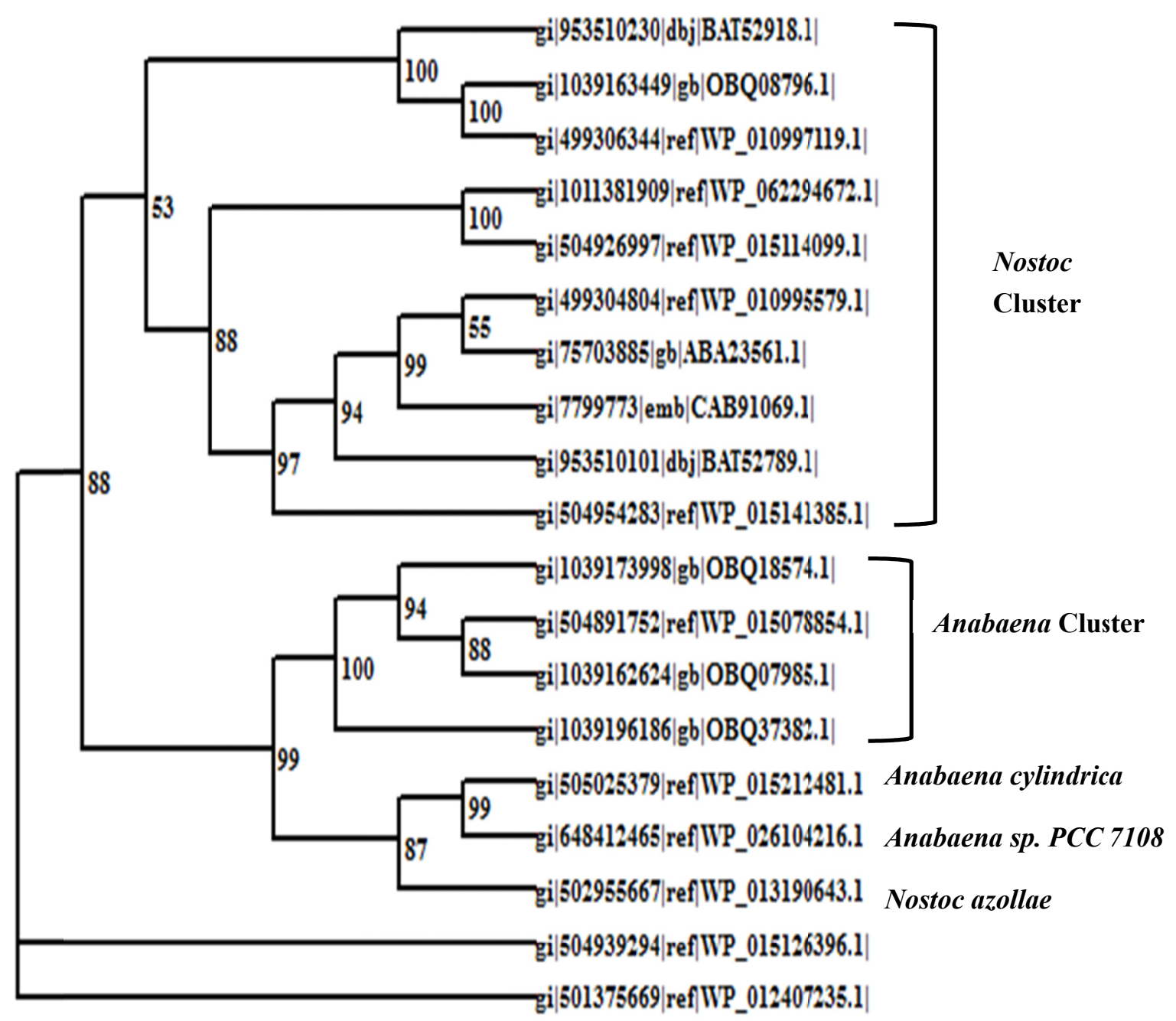

Figure 4. Phylogenetic tree created using the neighborhood joining method of phylogeny inference using 19 Nostocales homocitrate synthase protein sequences from the NCBI database (Anabaena - 10; Nostoc - 8; Calothrix -1 (outgroup)) The phylogenetic tree was inferred from the sequence alignment of the protein sequences using the above inference method supported by 500 bootstrap pseudo replications. 


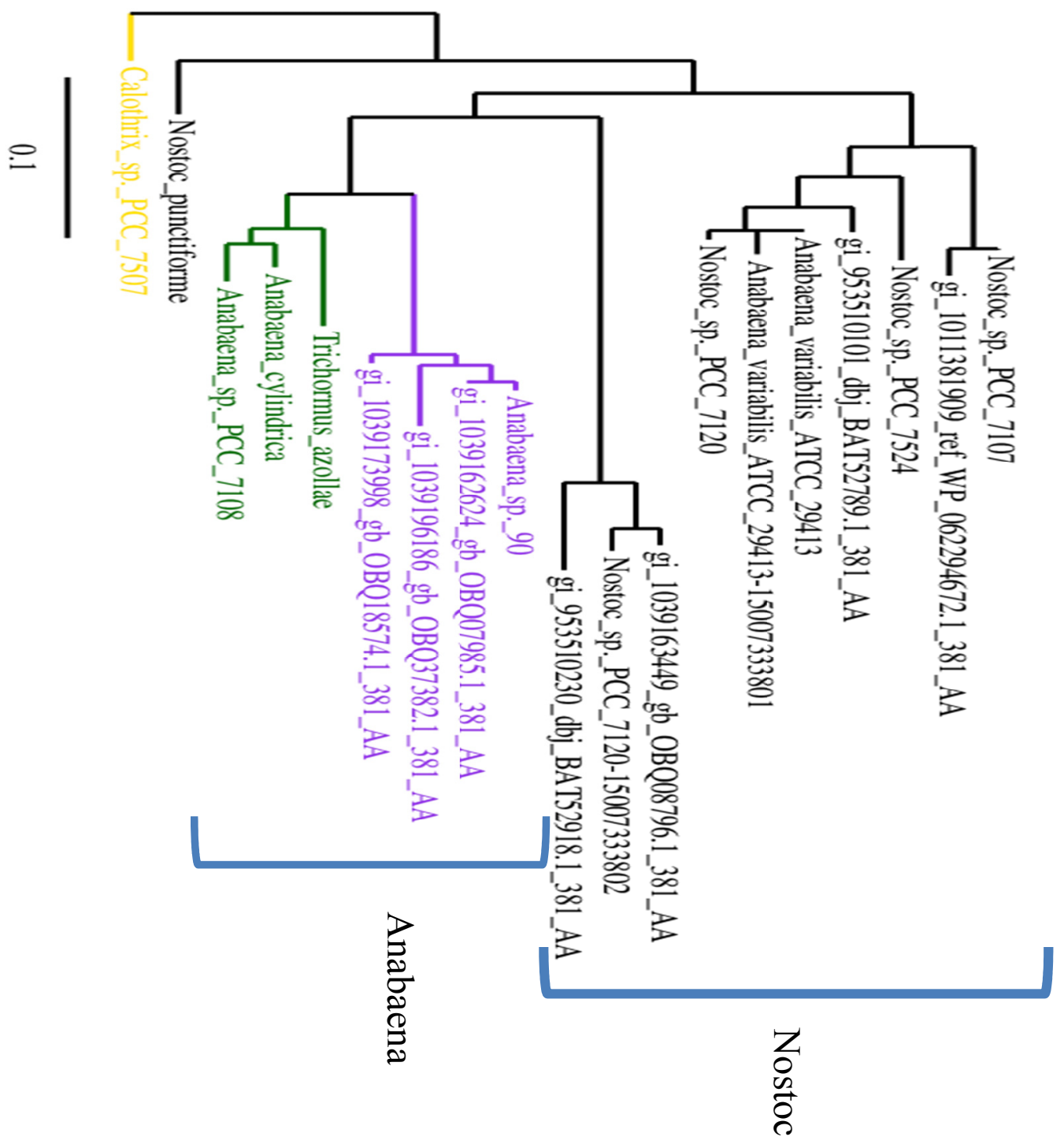

Figure 5. Phylogenetic tree created using the Phylogeny.fr platform. 19 Nostocales homocitrate synthase protein sequences from the NCBI database (Anabaena - 10; Nostoc - 8; Calothrix -1 (outgroup)) were used for the phylogenetic inferences. The sequences were aligned with the program Muscle (V.3.8.31) and ambiguous regions (i.e. containing gaps and/or poorly aligned sequences) were removed with Gblocks (v0.91b). The remaining sequences were used to reconstruct a phylogenetic tree, using the maximum likelihood method implemented in the PhyML program (v3.1/3.0 aLRT) and the tree was viewed using graphical representation with TreeDyn (v198.3). The Nostoc azollae NifV gene product is shown as Trichomus azollae in the figure.

\section{Acknowledgements}

This work was funded under Grant Number ASP/06/RE/SCI/2013/05, from the University of Sri Jayewardenepura. I also thank members of the Instrumentation Center (Faculty of Applied Sciences, University of Sri Jayewardenepura) especially Dr Asitha Cooray, and the technician Mr H.M.U.K.K Wijayasinghe, for undertaking the measurement of cadmium using AAS. I extend my gratitude to members of the Department of Statistics, University of Sri Jayewardenepura, who performed the pairwise comparisons. I thank Ms Uthapala Lekamge and Ms Isuru Gomes, for their valuable support in performing the final tank experiment.

\section{References}

Allen, R. M., Chatterjee, R., Madden, M. S., Ludden, P. W., Shah, V. K. (1994). Biosynthesis of the 
iron-molybdenum cofactor of nitrogenase. Critical reviews in biotechnology, 14, 225-249. https://doi.org/10.3109/07388554409079834

Baker, J. A., Entsch, B., \& McKay, D. B. (2003). The cyanobiont in an Azolla fern is neither Anabaena nor Nostoc. FEMS microbiology letters, 229, 43-47. https://doi.org/10.1016/S0378-1097(03)00784-5

Bauntiyal, M., \& Sharma, V. (2014). Response of fluoride stress to alter plasma membrane associated $\mathrm{H}^{+}$ATPases ( $\mathrm{P}$ type) and vacuolar membrane associated $\mathrm{H}^{+}$ATPases (V type) activity in semi-arid plants. Indian Journal of Plant Physiology, 19(3), 210-214. https://doi.org/10.1007/s40502-014-0103-x

Bediako, E. O. (2013). Potential of Addinatum raddianum and Neprolepis exaltata for phytoextraction of heavy metals in spiked soils. M. Sc. Thesis, Department of Environmental Science, Kwame Nkrumah University of Science and Technology, Ghana.

Capone, S., De Robertis, A., De Stefano, C., \& Sammartano, S. (1986). Formation and stability of zinc(II) and cadmium(II) citrate complexes in aqueous solution at various temperatures. Talanta, 33, 763-767. https://doi.org/10.1016/0039-9140(86)80184-9

Carpene, E., Andreani, G., \& Isani, G. (2007). Metallothionein functions and structural characteristics. Journal of trace elements in medicine and biology: organ of the Society for Minerals and Trace Elements, 21(Suppl 1), 35-39. https://doi.org/10.1016/j.jtemb.2007.09.011

Chandrajith, R., Ariyaratne, T., \& Dissanayaka, C. B. (2012). The status of cadmium in the geo-environment in Sri Lanka. The Ceylon Journal Of Science, 16, 47-53.

Cheng, M., Wang, P., Kopittke, P. M., Wang, A., Sale, P. W., \& Tang, C. (2016). Cadmium accumulation is enhanced by ammonium compared to nitrate in two hyperaccumulators, without affecting speciation. Journal of experimental botany. https://doi.org/10.1093/jxb/erw270

Darnajoux, R., Constantin, J., Miadlikowska, J., Lutzoni, F., \& Bellenger, J. P. (2014). Is vanadium a biometal for boreal cyanolichens? The New phytologist, 202, 765-771. https://doi.org/10.1111/nph.12777

Dereeper, A., Guignon, V., Blanc, G., Audic, S., Buffet, S., Chevenet, F., ... Gascuel, O. (2008). Phylogeny.fr: robust phylogenetic analysis for the non-specialist. Nucleic Acids Res., 1, 36. https://doi.org/10.1093/nar/gkn180

Eren, E., \& Arguello, J. M. (2004). Arabidopsis HMA2, a divalent heavy metal-transporting P(IB)-type ATPase, is involved in cytoplasmic $\mathrm{Zn} 2+$ homeostasis. Plant physiology, 136, 3712-3723. https://doi.org/10.1104/pp.104.046292

Frassinetti, S., Bronzetti, G., Caltavuturo, L., Cini, M., \& Croce, C. D. (2006). The role of zinc in life: a review. Journal of environmental pathology, toxicology and oncology: official organ of the International Society for $\begin{array}{llll}\text { Environmental Toxicology } & \text { Cancer, } & \text { 597-610. }\end{array}$ https://doi.org/10.1615/JEnvironPatholToxicolOncol.v25.i3.40

Hakoyama, T. et al. (2009). Host plant genome overcomes the lack of a bacterial gene for symbiotic nitrogen fixation. Nature, 462, 514-517. https://doi.org/10.1038/nature08594

Hodkinson, B. P., Allen, L. L., Forrest, B., Goffinet, B., Serusiaux, E., Andresson, S., ... Lutzoni, F. (2014). Lichen-symbiotic cyanobacteria associated with Peltigera have an alternative vanadium-dependent nitrogen fixation. European Journal of Phycology, 19, 11-19. https://doi.org/10.1080/09670262.2013.873143

Jaywardana, D. T., Pitawala, H. M. T. G. A., \& Ishiga, H. (2014). Geochemical evidence for the accumulation of vanadium in soils of chronic kidney disease areas in Sri Lanka. Environ Earth Sci.

Kalra, Y. P. (1998). Handbook of reference methods for plant analysis. Soil and Plant Analysis Council, CRC Press, Taylor \& Francis Group.

Komarek, J., Kastovsky, J., Mares, J., \& Johanson, J. R. (2014). Taxonomic classification of cyanoprokaryotes (cyanobacterial genera) 2014, using a polyphasic approach. Preslia, 86, 195-335.

Lyra, C., Suomalainen, S., Gugger, M., Vezie, C., Sundman, P., Paulin, L., \& Sivonen, K. (2001). Molecular characterization of planktic cyanobacteria of Anabaena, Aphanizomenon, Microcystis and Planktothrix genera. International journal of systematic and evolutionary microbiology, 51, 513-526. https://doi.org/10.1099/00207713-51-2-513

McLean, J. E., Pabst, M. W., Miller, C. D., Dimkpa, C. O., \& Anderson, A. J. (2013). Effect of complexing ligands on the surface adsorption, internalization, and bioresponse of copper and cadmium in a soil 
bacterium. Pseudomonas putida Chemosphere, 91, 374-382. https://doi.org/10.1016/j.chemosphere.2012.11.071

Meeks, J. C., Joseph, C. M., \& Haselkorn, R. (1988). Organization of the nif genes in cyanobacteria in symbiotic association with Azolla and Anthoceros. Archives of microbiology, 150, 61-71. https://doi.org/10.1007/BF00409719

Pereira, A. L., \& Vasconcelos, V. (2014). Classification and phylogeny of the cyanobiont Anabaena azollae Strasburger: an answered question? International journal of systematic and evolutionary microbiology, 64, 1830-1840. https://doi.org/10.1099/ijs.0.059238-0

Peters, G. A. (1991). Azolla and other plant-cyanobacterial symbioses: Aspects of form and function. Plant and Soil, 137(1), 25-37. https://doi.org/10.1007/BF02187428

Rai, P. K. (2008). Phytoremediation of $\mathrm{Hg}$ and $\mathrm{Cd}$ from industrial effluents using an aquatic free floating macrophyte Azolla pinnata. International journal of phytoremediation, 10, 430-439. https://doi.org/10.1080/15226510802100606

Rehder, D. (2008). Is vanadium a more versatile target in the activity of primordial life forms than hitherto anticipated? Organic \& biomolecular chemistry, 6, 957-964. https://doi.org/10.1039/b717565p

Salt, D. E., Blaylock, M., Kumar, N. P., Dushenkov, V., Ensley, B. D., Chet, I., \& Raskin, I. (1995). Phytoremediation: a novel strategy for the removal of toxic metals from the environment using plants. Bio/technology, 13, 468-474. https://doi.org/10.1038/nbt0595-468

Schor-Fumbarov, T., Goldsbrough, P. B., Adam, Z., \& Tel-Or, E. (2005). Characterization and expression of a metallothionein gene in the aquatic fern Azolla filiculoides under heavy metal stress. Planta, 223, 69-76. https://doi.org/10.1007/s00425-005-0070-6

Sood, A., Uniyal, P. L., Prasanna, R., \& Ahluwalia, A. S. (2012). Phytoremediation potential of aquatic macrophyte, Azolla. Ambio, 41, 122-137. https://doi.org/10.1007/s13280-011-0159-z

Takahashi, R., Bashir, K., Ishimaru, Y., Nishizawa, N. K., \& Nakanishi, H. (2012). The role of heavy-metal ATPases, HMAs, in zinc and cadmium transport in rice. Plant signaling \& behavior, 7, 1605-1607. https://doi.org/10.4161/psb.22454

Talley, S. N., Talley, B. J., \& Rains, D. W. (1977). Nitrogen fixation by Azolla in rice fields. Basic life sciences, 9, 259-281. https://doi.org/10.1007/978-1-4684-0880-5_17

Thayaparan, M., Iqbal, S. S., Chathuranga, P. K. D., \& Iqbal, M. C. M. (2013). Rhizofiltration of Pb by Azolla pinnata. International Journal of Environmental Sciences, 3(6).

Thiel, T. (1993). Characterization of genes for an alternative nitrogenase in the cyanobacterium Anabaena variabilis. Journal of bacteriology, 175, 6276-6286. https://doi.org/10.1128/jb.175.19.6276-6286.1993

Wasana, H. M., Aluthpatabendi, D., Kularatne, W. M., Wijekoon, P., Weerasooriya, R., \& Bandara, J. (2016). Drinking water quality and Chronic Kidney Disease of an Unknown Etiology: Synergistic effects of fluoride, cadmium, and hardness of water. Environmental geochemistry and health, 38(1), 157-168. https://doi.org/10.1007/s10653-015-9699-7

Wimalawansa, S. J. (2016). The role of ions, heavy metals, fluoride, and agrochemicals: critical evaluation of potential aetiological factors of chronic kidney disease of multifactorial origin $(\mathrm{CKDmfo} / \mathrm{CKDu})$ and recommendations for its eradication. Environmental geochemistry and health, 38, 639-678. https://doi.org/10.1007/s10653-015-9768-y

Xia, X., \& Xie, Z. (2001). DAMBE: software package for data analysis in molecular biology and evolution. The Journal of heredity, 92, 371-373. https://doi.org/10.1093/jhered/92.4.371

Zayed, A., Gowthaman, S., \& Terry, N. (1998). Phytoremediation of trace elements by wetland plants: Duck weed. J Environ Qual., 27(3), 715-721. https://doi.org/10.2134/jeq1998.00472425002700030032x

\section{Copyrights}

Copyright for this article is retained by the author(s), with first publication rights granted to the journal.

This is an open-access article distributed under the terms and conditions of the Creative Commons Attribution license (http://creativecommons.org/licenses/by/4.0/). 